\title{
ARBITRAJE COMERCIAL INTERNACIONAL Y TUTELA CAUTELAR: COLABORACIÓN ENTRE JUECES Y ÁRBITROS EN LA ADOPCIÓN Y RECONOCIMIENTO DE MEDIDAS CAUTELARES INTERNACIONALES
}

\author{
INTERNATIONAL COMMERCIAL ARBITRATION AND PRECAUTIONARY \\ PROTECTION: THE COLLABORATION BETWEEN JUDGES \\ AND ARBITRATORS IN THE ADOPTION AND RECOGNITION \\ OF INTERNATIONAL PRECAUTIONARY MEASURES
}

\author{
Víctor Rogelio Sueiro Varhen \\ Pontificia Universidad Católica del Perú
}

When referring to international commercial arbitration in Peru, two questions that have received little doctrinary reflection arise. These are, on one hand, the possibility that a Peruvian court may adopt a precautionary measure in assistance of a commercial arbitration based abroad and, on the other hand, the possibility of recognition by the Peruvian courts of a precautionary measure issued in the context of a commercial arbitration based abroad. They constitute the two sides of the same legal problem to which the author aims to reply by proposing a solution through a solid argumentative development.

In this article, the author's analysis departs from the importance of the right to effective international judicial protection, emphasizing on international precautionary protection. Moreover, he reflects on the duty of cooperation of the state courts in order to safeguard the effectiveness of precautionary protection in international commercial arbitration. At last, the author proposes certain criteria or parameters that would come in useful for the Peruvian state courts in order to adopt and recognize precautionary measures in support of international commercial arbitration when based abroad.

KEYWORDS: International commercial arbitration; effective international judicial protection; international precautionary measure; recognition of precautionary measures; judicial intervention aid.
En el Perú, al referirnos al arbitraje comercial internacional, encontramos dos interrogantes que, hasta el momento, han merecido escasa reflexión doctrinaria. Estas son, por un lado, la posibilidad de que un tribunal peruano adopte una medida cautelar en auxilio de un arbitraje comercial con sede en el extranjero; $y$, de otro lado, la posibilidad de reconocimiento por los tribunales peruanos de una medida cautelar dictada en el ámbito de un arbitraje comercial con sede en el extranjero. Son las dos caras de un mismo problema al que el autor, sobre la base de una sólida argumentación, busca dar respuesta.

En el presente artículo, el autor inicia su análisis a partir de la importancia del derecho a la tutela jurisdiccional internacional efectiva, con énfasis en la tutela cautelar internacional. Posteriormente, aborda el deber de cooperación de los tribunales estatales para salvaguardar la eficacia de la tutela cautelar en el arbitraje comercial internacional. Finalmente, el autor propone ciertos criterios o parámetros que resultarán útiles para los tribunales estatales peruanos a fin de que puedan adoptar y reconocer medidas cautelares en apoyo a un arbitraje comercial internacional con sede en el extranjero.

PALABRAS CLAVE: Arbitraje comercial internacional; tutela jurisdiccional internacional efectiva; medida cautelar internacional; reconocimiento de medidas cautelares; intervención judicial de apoyo.

\footnotetext{
Abogado. Máster en Derecho, Empresa y Justicia por la Universitat de València con estudios de posgrado en Derecho Procesal por la Pontificia Universidad Católica del Perú (PUCP). Profesor de Derecho Internacional Privado en la Facultad de Derecho de la PUCP (Lima, Perú). Contacto: victor.sueiro@pucp.pe.
}

Nota del Editor: El presente artículo fue recibido por el Consejo Ejecutivo de THËMIS-Revista de Derecho el 12 de marzo de 2020 y aceptado por el mismo el 26 de junio de 2020. 


\section{INTRODUCCIÓN}

Uno de los objetivos primordiales del desarrollo de la justicia transfronteriza relativa a controversias del comercio internacional es lograr que la tutela cautelar se despliegue de manera efectiva. La inevitable existencia de numerosos derechos estatales genera un fraccionamiento jurídico territorial que puede menoscabar dicho objetivo. La tutela cautelar, al ser una manifestación jurídica estatal reconocida en los últimos años al arbitraje, no es ajena a este fenómeno. Por ello, podríamos afirmar que existe un fraccionamiento territorial con respecto a la tutela cautelar en los órganos estatales y el arbitraje. Aunado a esto, el fraccionamiento de los servicios judiciales provoca que lograr la eficacia de la tutela cautelar en las controversias del comercio internacional requiera mayor tiempo.

La adopción de medidas cautelares en apoyo de un arbitraje extranjero y el reconocimiento de laudos extranjeros que contienen una decisión cautelar son dos caras de la misma moneda. Por un lado, surge la interrogante de la adopción de una medida cautelar con vocación de extraterritorialidad; $y$, por otro, el reconocimiento de una medida cautelar dictada por un tribunal arbitral con sede en el extranjero, competente en la esfera internacional. Esto se dificulta aún más en el arbitraje comercial internacional, en que los árbitros carecen de ius imperium. Nos queda, entonces, la interrogante acerca de cómo confluye el arbitraje comercial internacional con la justicia estatal.

En el presente artículo, abordaremos la cooperación entre los tribunales estatales y arbitrales para la adopción de medidas cautelares en apoyo de un arbitraje comercial internacional; así como el reconocimiento y ejecución de medidas cautelares emitidas en el marco de un arbitraje comercial internacional, el cual puede requerir que se adopten, reconozcan y/o ejecuten en distintos Estados, distintos del lugar sede del arbitraje. Para ello, enfatizaremos en la internacionalidad del arbitraje, a fin de diferenciar sus características y particularidades respecto del arbitraje nacional o doméstico. En ese sentido, consideramos que un estudio acerca de la potestad de los árbitros de dictar medidas cautelares en un arbitraje comercial internacional se aparta del objeto del presente artículo.

\section{EL ARBITRAJE COMO MEDIO COMPLEMEN- TARIO A LA JUSTICIA CONVENCIONAL}

El inevitable crecimiento de casos planteados ante tribunales arbitrales y la litigiosidad en estos supone un reto actual para que el Estado garantice una tutela jurisdiccional efectiva (Barona Vilar, 2016, p. 51) ${ }^{1}$. Más aún, esto se ve agudizado en los litigios transfronterizos, en los que surgen cuestiones de competencia judicial internacional, derecho aplicable al procedimiento, derecho aplicable al fondo de la controversia (derecho nacional o extranjero) $y$, finalmente, reconocimiento de sentencias y laudos emitidos en el extranjero, lo cual dota de una exponencial complejidad no solo al proceso judicial, sino también al arbitraje, generando una inevitable dilación en el tiempo. Esta complejidad internacional afecta a la tutela jurisdiccional efectiva.

Como menciona el profesor Esplugues Mota,

el aumento de la litigiosidad con elementos de extranjería en un mundo globalizado constituye un signo distintivo de nuestros días que, de manera adicional, acentúa la presión sobre el sistema estatal de justicia, poniendo en jaque su capacidad real para asegurar de forma efectiva la virtualidad del principio de acceso a la justicia para la ciudadanía (2019, p. 52).

En este contexto, los Estados reconocen el valor del arbitraje como un medio alternativo de solución de conflictos, nacido para salvaguardar los intereses de las partes en sus relaciones comerciales internacionales. Es aquí, donde surge la Ley Modelo de la Comisión de las Naciones Unidas para el Derecho Mercantil Internacional de 1985 (en adelante, la Ley Modelo de la CNUDMI). Esta sirvió como modelo para las diferentes legislaciones nacionales, las cuales adoptaron sus leyes de arbitraje comercial nacional e internacional. El arbitraje es una categoría autónoma, en tanto que solo es posible hablar de este si se toman en cuenta todas las categorías doctrinales que buscaron definirlo. Sería un error encasillarlo en una sola. En consecuencia, "el arbitraje es arbitraje, y esa es su naturaleza jurídica" (Barona Vilar, 2007, p. 46).

Ahora bien, a fin de garantizar la tutela jurisdiccional efectiva a los ciudadanos, este mecanismo alternativo de solución de conflictos no está exento de control por parte del Estado. Desde una pers-

\footnotetext{
La autora se refiere a la misma como "tutela judicial efectiva" (Barona Vilar, 2016, p. 51). De igual manera lo hacen autores como Virgós Soriano y Garciamartín Alférez (2007, pp. 37-41). Para efectos de este artículo, utilizaremos el término jurisdiccional que, a nuestro criterio, es más amplio en tanto que se refiere a la atribución de los tribunales estatales y arbitrales para ejercer función jurisdiccional.
} 
pectiva legislativa, en un Estado Constitucional de Derecho, las reglas se crean en el Poder Legislativo, el cual aprueba la Ley de Arbitraje. Asimismo, desde el punto de vista judicial, este control lo efectúan los tribunales estales a través del control de validez del laudo arbitral (anulación), la ejecución del laudo, la actuación de medios probatorios, la adopción y la ejecución de medidas cautelares en apoyo de un arbitraje, entre otras actuaciones.

Esta última relación entre el arbitraje y el Poder Judicial, nos permite concluir que no se trata de vías de solución de conflictos incompatibles. Todo lo contrario. La finalidad de ambas es tutelar el interés supremo del Estado: otorgar una óptima satisfacción del derecho a la tutela jurisdiccional efectiva, tanto en el plano nacional como en el internacional.

Pese a su notorio éxito como método alternativo, el arbitraje debe alejarse del que pretende hacer de este el único mecanismo válido para la resolución de controversias jurídicas internacionales. Ello pues, para lograr su verdadera meta, debe cooperar con los sistemas legislativos del lugar donde se desarrolla, es decir, de su sede. Si bien es cierto que los árbitros están sometidos a los intereses privados de las partes, actualmente se reconoce que, de cierta manera, también se encuentran sujetos a la obligación más amplia que es velar por la justicia (Radicati di Brozolo, 2013, p. 215).

\section{EL ELEMENTO INTERNACIONAL EN EL ARBI- TRAJE COMERCIAL}

De manera previa a este análisis cabe preguntarnos lo siguiente: ¿la naturaleza del arbitraje es una materia controvertida en el Perú? ¿Cuál de las teorías ha prevalecido? Un sector de la doctrina peruana sostiene que el Tribunal Constitucional del Perú, a través de la sentencia recaída en el Expediente 6167-2005-PHC/TC, de 28 de enero de $2006^{2}$, colocó al arbitraje en la teoría jurisdiccional

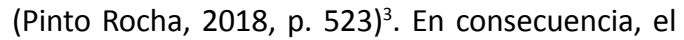
arbitraje en el Perú, nacional o internacional, es jurisdicción, reconocida como tal en el artículo $139^{4}$ de la Constitución Política del Perú. Por ende, al ser el arbitraje jurisdicción según el Tribunal Constitucional, este mecanismo alternativo de solución de controversias debe salvaguardar la finalidad última del proceso: la tutela jurisdiccional efectiva de los ciudadanos, la cual engloba a la tutela cautelar.

Resulta necesario determinar cuándo estamos frente a un arbitraje comercial de carácter nacional o internacional, así como sus principales consecuencias. La tendencia a la codificación internacional del arbitraje comercial se presentó de manera temprana en América Latina. El primer antecedente se concretó pocos años tras la era de las emancipaciones de los países americanos con los tratados de derecho internacional privado, entre ellos, los Tratados de Derecho Procesal Civil Internacional de Montevideo de $1889-1890$ y de $1939-1940^{5}$. En estos, por primera vez en el plano internacional americano, se otorgó a los laudos arbitrales -independientemente del Estado parte donde hayan sido emitidos- un tratamiento similar al de las sentencias dictadas por tribunales estatales (All \& Pallarés, 2019, pp. 100-102).

En los últimos 40 años, América Latina ha continuado con esa incesante labor codificadora estatal en relación con el arbitraje comercial internacional. El común denominador de las reformas legislativas es la adopción de la Ley Modelo de la CNUDMI. Este texto que ha sido empleado por los legisladores estatales de la mayor parte de los Estados de Latinoamérica, en la mayoría de los casos, ha conducido a eliminar la "dispersión legislativa" existente, otorgándole autonomía normativa a la reglamentación del proceso arbitral (Palao Moreno, 2007, pp. 218-219).

Actualmente, los tratados sobre la materia, las normas nacionales, la jurisprudencia y la doctrina

Ninguna persona puede ser desviada de la jurisdicción predeterminada por la ley, ni sometida a procedimiento distinto de los previamente establecidos, ni juzgada por órganos jurisdiccionales de excepción ni por comisiones especiales creadas al efecto, cualquiera sea su denominación (Const., 1993).

5 De ambos tratados, Perú ratificó únicamente el Tratado de Derecho Procesal Civil Internacional de 1889. 
tienen diversas tendencias sobre cómo diferenciar el tema. Podemos identificar dos principales tendencias (Sandler Obregón, 2016, p. 438):

a) Subjetiva: esta guarda relación con las partes en la disputa arbitral. Un arbitraje será internacional cuando el lugar de domicilio, residencia habitual o lugar de negocios de las partes se encuentren en distintos Estados.

b) Objetiva: se enfoca en la naturaleza de la controversia arbitral. Un arbitraje será internacional cuando comprenda intereses del comercio internacional.

El artículo primero de la Ley Modelo de la CNUDMI califica de internacional a un arbitraje de varias maneras. El primer criterio es si las partes, al momento de la celebración del acuerdo de arbitraje, tienen establecimientos (domicilio) en Estados diferentes. El segundo y tercer criterio son si el lugar del arbitraje (sede del arbitraje) o el lugar del cumplimiento de una parte esencial de las obligaciones de la relación contractual están en diferentes Estados. Finalmente, el cuarto criterio otorga la posibilidad a las partes de convenir expresamente que la cuestión sometida a arbitraje estará relacionada con más de un Estado.

Como vemos, el artículo primero de la Ley Modelo de la CNUDMI recoge ambas tendencias, por lo que consideramos da un significado amplio del arbitraje comercial internacional. En otras palabras, el carácter interno o internacional del arbitraje no depende del lugar de la sede, nacionalidad o domicilio de las partes, la ley aplicable al fondo o el procedimiento, ni la voluntad de las partes; sino de que el negocio de la controversia implique un desplazamiento de bienes, servicios o dinero (Fernández Rozas et al., 2011, p. 635).

Asimismo, en términos de derecho internacional privado, un arbitraje comercial será de carácter internacional cuando se presente como una relación privada internacional (Delgado Barreto et al., 2010, pp. 30-37). Es decir, el arbitraje es una relación jurídica privada que le compete a dos personas naturales y/o jurídicas privadas (incluyendo al Estado, siempre y cuando actúe con su ius gestionis); existe en la relación privada un elemento internacional o extranjero (por ejemplo, domicilio de las partes, lugar de ejecución del contrato, lugar de celebración del arbitraje); y, este elemento internacional o extranjero es relevante, no accidental ${ }^{6}$.

A su vez, una diferencia sustancial entre el arbitraje nacional con en el arbitraje comercial internacional, es que existen diferentes reglas de fuente nacional e internacional que interactúan entre ellas: "these rules have their origin in public international law, private international law and intergovernmental and non-government instruments which have developed procedures and practices that have wide international acceptance"7 (Lew, 2006 , p. 182). Ello implica que -a diferencia del arbitraje nacional- en el arbitraje comercial internacional existen más fuentes legislativas, de carácter internacional, que interactúan con el desarrollo del proceso arbitral.

Por otro lado, la noción de sede en el arbitraje comercial internacional comprende un territorio donde se van a efectuar las operaciones materiales del proceso arbitral. Esta selección crea un vínculo entre el arbitraje y el lugar, siendo este último una "referencia estatal" que proveerá una asistencia judicial y disminuirá el grado de inseguridad negativo para el desarrollo del proceso arbitral (Fernández Rozas et al., 2011, p. 640).

Siguiendo la Exposición de Motivos del Decreto Legislativo 1071 (en adelante, Ley de Arbitraje peruana), esta puede ser calificada como monista. Es decir, establece que sus disposiciones regirán por igual tanto para el arbitraje comercial nacional como para el internacional:

\section{Artículo 1.- Ámbito de aplicación}

1. El presente Decreto Legislativo se aplicará a los arbitrajes cuyo lugar se halle dentro del territorio peruano, sea el arbitraje de carácter nacional o internacional; sin perjuicio de lo establecido en tratados o acuerdos internacionales de los que el Perú sea parte o en leyes que contengan disposiciones especiales sobre arbitraje, en cuyo caso las normas de este Decreto Legislativo serán de aplicación supletoria.

2. Las normas contenidas en los numerales 1 , 2, 3, 5 y 6 del artículo 8ㅇ, en los artículos 13으,

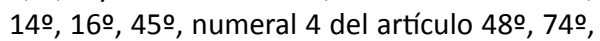
75으, 76으, 77ㅇ y 78 ㅇ de este Decreto Legislativo, se aplicarán aun cuando el lugar del arbitraje se halle fuera del Perú (Decreto Legislativo 1071, 2008)

En igual sentido, véase Esplugues Mota (2014, pp. 75-81).

$7 \quad$ Estas reglas tienen su origen en el derecho internacional público, el derecho internacional privado y los instrumentos intergubernamentales y no gubernamentales que han desarrollado procedimientos y prácticas altamente aceptados a nivel internacional [traducción libre]. 
Al igual que la Ley Modelo de la CNUDMI, el artículo 5 de la Ley de Arbitraje peruana ${ }^{8}$ considera que un arbitraje comercial será internacional cuando:

a) Las partes del arbitraje domicilien en diferentes Estados.

b) La sede del arbitraje esté localizada fuera del Perú.

c) El lugar del cumplimiento de la relación contractual se encuentre fuera del Perú.

Según lo expuesto, podemos concluir que un arbitraje con sede en Perú puede ser nacional o internacional; mas un arbitraje con sede en el extranjero siempre será internacional. En ese sentido, al arbitraje con sede en el extranjero se le aplicarán las disposiciones de la Ley de Arbitraje peruana en cuanto sean pertinentes, a fin de garantizar la tutela jurisdiccional efectiva de las partes. Esclarecer la diferencia entre el arbitraje nacional e internacional nos ayudará a determinar cómo opera la tutela cautelar en el ámbito del arbitraje comercial internacional, con especial énfasis en el arbitraje con sede en el extranjero y el reconocimiento de medidas cautelares dictadas fuera del Perú.

Finalmente, cabe preguntarnos si la tutela jurisdiccional efectiva tiene cabida en el plano internacional, específicamente en el arbitraje comercial internacional. La respuesta es afirmativa, pero debemos adecuar este principio a la realidad del arbitraje comercial internacional:

i. A través de una tutela por declaración: es decir, asegurar el acceso a las partes al arbitraje comercial internacional, lo cual implica reconocer su autonomía de la voluntad en pactar un arbitraje comercial internacional; $y$,

ii. A través de una tutela por reconocimiento: la cual implica reconocer la autoridad de cosa juzgada del laudo emitido en el extranjero.
Una de las instituciones que coadyuva al desarrollo eficiente del arbitraje comercial internacional es, sin duda, la medida cautelar. Independientemente de la forma que tengan (laudo u orden arbitral), las medidas cautelares deben garantizar la tutela jurisdiccional internacional efectiva, aun cuando las actuaciones arbitrales se realicen fuera del territorio nacional. Para ello, nos referiremos en el siguiente apartado a la cooperación entre los tribunales estatales y el arbitraje comercial internacional. Aquellos, lejos de entorpecer la tarea del arbitraje, coadyuvan a su finalidad.

\section{INTERVENCIÓN JUDICIAL DE APOYO EN LA ADOPCIÓN DE MEDIDAS CAUTELARES EN EL ARBITRAJE COMERCIAL INTERNACIONAL}

Un defecto del proceso judicial -del que no está exceptuado el arbitraje- es su duración. No actúa de manera inmediata sino que, por su naturaleza, requiere del paso del tiempo para que la protección de la tutela sea efectiva. Este aspecto se agudiza en un proceso o arbitraje comercial internacional, cuyos actos procesales, así como la complejidad de los temas discutidos, suelen requerir aún más tiempo. Este es uno de los fundamentos de la tutela cautelar.

La doctrina procesal clásica señala que las medidas cautelares permiten al proceso "asegurar preventivamente los medios idóneos para hacer que la providencia pueda tener, al ser dictada, la misma eficacia y el mismo rendimiento práctico que tendría si se hubiese dictado inmediatamente" (Calamandrei, 1945, pp. 43-44). Esto quiere decir que, la necesidad de resolver con prontitud el arbitraje se enfrenta con la necesidad de hacerlas bien. Esto sirvió de base para doctrinas contemporáneas, que definen la tutela cautelar como "a remedy or a relief that is aimed at safeguarding the rights of parties to a dispute pending its final resolution"9 (Yesilirmak, 2005, p. 4). Consideramos que las medidas cautelares son herramientas que buscan asegurar o defender un derecho de una de las par-

8 Cuya redacción es como sigue:

Artículo 5.- Arbitraje comercial internacional

1. El arbitraje tendrá carácter internacional cuando en él concurra alguna de las siguientes circunstancias:

a. Si las partes en un convenio arbitral tienen, al momento de la celebración de ese convenio, sus domicilios en Estados diferentes.

b. Si el lugar del arbitraje, determinado en el convenio arbitral o con arreglo a éste, está situado fuera del Estado en que las partes tienen sus domicilios.

c. Si el lugar de cumplimiento de una parte sustancial de las obligaciones de la relación jurídica o el lugar con el cual el objeto de la controversia tiene una relación más estrecha, está situado fuera del territorio nacional, tratándose de partes domiciliadas en el Perú.

2. Para efectos de lo dispuesto en el numeral anterior, si alguna de las partes tiene más de un domicilio, se estará al que guarde una relación más estrecha con el convenio arbitral (Decreto Legislativo 1071, 2008).

9 Un remedio que apunta a salvaguardar los derechos de las partes de un conflicto en espera de su resolución definitiva [traducción libre]. 
tes, evitando un perjuicio irreparable, siempre que cumplan para su concesión -al menos en el Perúlos requisitos de (i) fumus boni iuris; (ii) periculum in mora; y (iii) adecuación de la medida.

¿Es necesaria la tutela cautelar en el arbitraje comercial internacional? Por supuesto. Al ser las medidas cautelares el eje central de la tutela cautelar, su importancia en el arbitraje es fundamental, pues coadyuvan a garantizar la efectividad de un eventual laudo arbitral, así como la integridad del arbitraje mismo (Rodríguez Mejía, 2013, pp. 27-28). Incluso, esta trascendencia se ha visto plasmada en la creación de la figura del árbitro de emergencia ${ }^{10}$, que busca dar eficiencia al arbitraje y las medidas cautelares en conjunto. De esta manera, se estaría asegurando el cumplimiento del laudo final a cabalidad. Uno de los aspectos más invocados por los usuarios del arbitraje internacional responde a la eficiencia y flexibilización del arbitraje frente a los órganos jurisdiccionales (Esis Villarroel, 2019, p. 43) ${ }^{11}$.

Atendiendo al contenido de efectividad del derecho a la tutela jurisdiccional internacional efectiva, es necesario que exista una tutela de urgencia que permita hacer frente al tiempo en el proceso arbitral. La base de esa efectividad se asienta en la Constitución Política del Perú, la cual, a través de su desarrollo legislativo, otorga a jueces y/o árbitros la posibilidad de adoptar medidas cautelares. En ese sentido, se lesionaría el derecho a la tutela jurisdiccional internacional efectiva si una situación contraria al ordenamiento jurídico que se debe remediar resultase irreversible por no haberse adoptado una medida cautelar.

En el contexto internacional, las medidas cautelares pueden desplegar efectos fuera del lugar donde fueron dictadas. Podríamos definir la medida cautelar internacional como aquel instrumento procesal con vocación de extraterritorialidad destinado a garantizar la eficacia de la futura sentencia o laudo (nacional o extranjero) que, a petición de parte, requiera ser reconocido y ejecutado en un Estado extranjero, mediante una incidencia en la esfera jurídica del demandado. Al hablar de vocación de extraterritorialidad, hacemos referencia a que estas medidas tienen la aptitud de incidir en la esfera jurídica material de bienes situados en el extranjero; o que son necesarias para el desarrollo de un proceso estatal o arbitral extranjero, como es el caso de las medidas cautelares de carácter urgente adoptadas y ejecutadas por un tribunal estatal sobre bienes que se encuentran en su territorio, en auxilio de un proceso o arbitraje extranjero ${ }^{12}$.

En esta definición incluimos a las medidas cautelares destinadas a asegurar la efectividad de la sentencia o laudo extranjeros durante el proceso de reconocimiento o exequatur porque -pese a tener carácter de cosa juzgada, de manera que ponen fin al proceso judicial o arbitral-, a priori, estas no gozan del carácter de ejecutable como las sentencias y laudos nacionales. Esto se traduce en el riesgo de que lo decidido en el arbitraje comercial internacional con sede en el extranjero llegue demasiado tarde.

Así, podemos calificar como medidas cautelares internacionales vinculadas al arbitraje comercial internacional las siguientes:

- $\quad$ medidas cautelares adoptadas por un tribunal estatal o arbitral con competencia judicial internacional sobre el fondo acerca de bienes o personas localizadas fuera del lugar del territorio nacional del juez o la sede del arbitraje comercial internacional,

- medidas cautelares adoptadas por un tribunal estatal con competencia judicial internacional para conocer el proceso de reconocimiento o exequátur de sentencias y/o laudos extranjeros,

- medidas cautelares territoriales adoptadas por un tribunal estatal o arbitral (árbitro de emergencia) sin competencia judicial internacional sobre el fondo, pero por la urgencia de la tutela, con competencia para adoptar medidas cautelares sobre bienes y/o personas sobre el territorio donde se sitúan el tribunal estatal y o el arbitral.

En ese sentido, podemos concluir que existe un doble esquema que permite a la parte necesitada de tutela, acudir al (i) tribunal estatal o arbitral que conocerá sobre el fondo (foro principal) o al (ii) tribunal estatal o arbitral donde las medidas deben tomar efecto (foro especial). Este esquema, reconocido para el derecho procesal civil internacional, es también válido para el arbitraje comercial internacional (Virgós Soriano \& Garcimartín Alférez,

10 Por razones de espacio y contenido, en este artículo nos referiremos a la cooperación entre los órganos estatales y arbitraje internacional, excluyendo a los árbitros de emergencia y su desarrollo en los modernos reglamentos de arbitraje.

11 En este contexto, el rol de las instituciones arbitrales es sumamente importante. Son estas las que -en su mayoría- administran los arbitrajes internacionales debido a la reputación y reconocimiento del que gozan entre el público experto, el cual pide mayor uso de las tecnologías para repotenciar la eficiencia en el arbitraje (Queen Mary University of London \& White \& Case, 2018).

12 En la misma línea, Tellechea Bergman (2017, p. 114). 
2007, p. 353). En el caso de la cooperación entre el Poder Judicial y el arbitraje, el tribunal arbitral funcionaría como el foro principal, mientras que los tribunales estatales del lugar donde se encuentran los bienes o personas como el foro especial.

\section{A. Principio de intervención mínima en el ar- bitraje en las medidas cautelares interna- cionales}

En el Perú, al igual que la mayoría de los sistemas jurídicos, partimos del reconocimiento de un principio de intervención mínima en el arbitraje comercial nacional e internacional (Born, 2014, pp. 999-1033). El acuerdo arbitral tiene un efecto negativo que implica la exclusión de la intervención de los tribunales de justicia.

Sea que nos encontremos ante un arbitraje comercial nacional o uno internacional, el principio de mínima intervención judicial debe acentuarse, atendiendo a que el arbitraje reposa en la autonomía de la voluntad de las partes. No obstante ello, este principio no debe ser entendido como un excluyente absoluto del Estado en la esfera del arbitraje; sino que, como su nombre lo indica, demanda una intervención mínima estatal, en aras de garantizar el correcto funcionamiento, autonomía, efectividad e integridad del arbitraje.

La intervención judicial de apoyo para la adopción de medidas cautelares es ejemplo de ello. En esta existe una regla competencial básica:

si la medida cautelar afecta a terceros ajenos al arbitraje, debe optarse por la medida cautelar judicial (auxilio judicial); si solo afecta a las partes del procedimiento o su cumplimiento puede ser satisfecho por ellas, la medida debe solicitarse al árbitro (Fernández Rozas et al., 2018, p. 112).

Finalmente, cabe preguntarnos si las partes pueden renunciar a la tutela cautelar. Un sector de la doctrina considera que esto es posible, en tanto existe una intervención mínima del Poder Judicial en el arbitraje, acorde al carácter disponible del arbitraje (Fernández Rozas et al., 2018, p. 114). En el mismo sentido, otro sector de la doctrina señala que, cuando las partes no hayan pactado expresamente en el convenio arbitral dispensarse de la tutela cautelar, se debe favorecer la competencia del juez nacional para la adopción de las medidas cautelares. Es decir, la autonomía de la voluntad, en este sentido, es absoluta (Virgós Soriano \& Garcimartín Alférez, 2007, pp. 356-357) ${ }^{13}$.

Nosotros consideramos que no es posible renunciar a la tutela cautelar en sede arbitral y/o judicial por los siguientes motivos:

a) En primer lugar, la tutela cautelar tiene carácter irrenunciable según la lex fori, es decir según la Constitución y la Ley de Arbitraje peruana, al ser un derecho comprendido en la tutela jurisdiccional efectiva.

b) En segundo lugar, si no existen otros medios idóneos para hacer cumplir las órdenes de los árbitros, sobre todo cuando estas pretenden exigirse a terceros, esto supone un obstáculo al correcto funcionamiento del arbitraje y la voluntad de las partes.

c) En tercer lugar, el reconocimiento de la competencia del juez para dictar medidas cautelares ante el vacío de la voluntad expresa de las partes de renunciar a la tutela cautelar, no hace más que reforzar nuestra postura acerca de la irrenunciabilidad de la tutela cautelar en el arbitraje.

La regla del artículo 1 sección 2 de la Ley Modelo de la CNUDMI establece que las disposiciones de esta norma serán obligatorias para los arbitrajes (nacionales e internacionales) en cuyo Estado se hayan incorporado. Esto significa que, de manera paralela a las reglas establecidas en el convenio arbitral, existe una prohibición general según la cual las partes y los árbitros no pueden excluir la aplicación de las normas imperativas del lugar de la sede del arbitraje. Como resultado de esta posición, el tribunal arbitral que lleva a cabo un arbitraje comercial internacional en el Perú se sujeta a las normas de carácter imperativo de este Estado, las cuales contemplan la tutela cautelar internacional.

Es tan importante el carácter imperativo de la cooperación cautelar entre los tribunales estatales y el arbitraje que, en resguardo de la autonomía de la voluntad de las partes, el artículo 47 numeral 4 de la Ley de Arbitraje peruana ${ }^{14}$ indica expresamente

13 En el mismo sentido, con más argumentos, consúltese Gómez Jene (2018, pp. 313-314).

14 Cuya redacción es la siguiente:

Artículo 47.- Medidas cautelares

4. Las medidas cautelares solicitadas a una autoridad judicial antes de la constitución del tribunal arbitral no son incompatibles con el arbitraje ni consideradas como una renuncia a él. Ejecutada la medida, la parte beneficiada deberá iniciar el arbitraje dentro de los diez (10) días siguientes, si no lo hubiere hecho con anterioridad. Si no lo hace dentro de este plazo o habiendo cumplido con hacerlo, no se constituye el tribunal arbitral dentro de los noventa (90) días de dictada la medida, ésta caduca de pleno derecho (Decreto Legislativo 1071) 
que las medidas cautelares solicitadas a los tribunales estatales no son incompatibles con el arbitraje, $y$ que mucho menos implican una renuncia al mismo.

\section{B. Cooperación de los jueces para la adopción de medidas cautelares en el arbitraje co- mercial internacional}

La solicitud de medidas cautelares ante la jurisdicción estatal es compatible con el arbitraje por los siguientes motivos:

- $\quad$ No implica una sumisión tácita: la solicitud de una medida cautelar en apoyo de un arbitraje a un tribunal estatal no implica una sumisión a este, ya que prevalece el convenio arbitral entre las partes que puede ser invocado en caso de interferencia del juez (Lapiedra Alcamí, 2003, pp. 219-220).

- No involucra una renuncia al arbitraje: no cabe una renuncia unilateral al arbitraje a través de una solicitud de medida cautelar. La tensión que supuestamente se encuentra entre el arbitraje y la jurisdicción estatal cuando una solicitud cautelar se dirige a este último no implica una renuncia al arbitraje (Lorca Navarrete, 1996, p. 801). Dicho esto, la interacción entre el arbitraje y los órganos estatales de justicia no son excluyentes, sino que se enmarcan en una cooperación.

Las funciones de cooperación o auxilio en el arbitraje comercial internacional son inevitables, en la medida en que los árbitros carecen de ius imperium para obligar a las partes, a través del uso de la fuerza pública, a cumplir sus resoluciones. Mucho se ha avanzado en esta materia al admitirse la naturaleza jurisdiccional del arbitraje y la atribución de los árbitros de dictar medidas cautelares. No es oportuno que el Estado otorgue a los árbitros funciones ejecutorias; el rol de ejecutor de las decisiones arbitrales está reservado para los jueces (Caivano, 2015, pp. 119-120).

En ese sentido, uno de los mayores efectos que tiene la elección de la sede es la función que cumplirán los jueces de prestar auxilio a las decisiones arbitrales que requieran de imperio. Así, la ley de la sede principal tendrá un papel fundamental en la adopción de medidas cautelares, sin vincularse con el fondo del proceso. Ante el arbitraje comercial internacional, el juez peruano actuaría como foro especial en auxilio del árbitro por las siguientes razones:

a) El tribunal arbitral no es permanente. Su constitución requiere tiempo y la posibilidad de adoptar medidas cautelares.

b) El proceso arbitral es, en esencia, contradictorio. Se pierde el factor sorpresa de la medida cautelar, el cual sí se mantiene al acudir a un tribunal estatal.

c) El tribunal arbitral no puede, en principio, adoptar medidas cautelares contra terceros que no formen parte del convenio arbitral.

d) El tribunal arbitral no dispone del ius imperium. Por ello, siempre va a requerir del auxilio de la fuerza pública.

En cuanto a la ley aplicable a la adopción de medidas cautelares en el proceso arbitral, la doctrina consagra dos criterios: (i) la autonomía de la voluntad; y, en defecto de esta, (ii) la ley de la sede arbitral, es decir, del país donde se desarrolla el arbitraje (Monroy, 2012, p. 466). En términos de derecho internacional privado, la ley que regula la posibilidad o no de adoptar medidas cautelares -sea por el juez o por el árbitro- es la lex loci arbitri, en tanto es la ley aplicable al procedimiento (Gómez Jene, 2018, p. 315).

En virtud de lo expuesto, para solicitar una medida cautelar ante un tribunal judicial peruano para hacerse valer en el Perú en apoyo de un arbitraje comercial internacional (con sede en este Estado o en el extranjero), deberemos tomar en cuenta la posible aplicación de normas de fuente internacional y, en su defecto, nacional. Para ello, a continuación, analizaremos si existen textos legales que regulan este apoyo y la medida en que son aplicables.

\section{Normas de fuente internacional}

Algunos autores nacionales e internacionales sostienen que la Convención sobre Derecho Internacional Privado sobre Medidas Cautelares de 1979 (en adelante, CIDIP II), ratificada por el Perú en $1980^{15}$, es aplicable para la adopción de medidas cautelares en apoyo de un arbitraje comercial internacional ${ }^{16}$. En principio, sí es aplicable; sin embargo, consideramos que debemos precisar los alcances de este en el arbitraje comercial internacional.

\footnotetext{
15 Para mayor información sobre el estado de la ratificación de la CIDIP II, consúltese Organización de los Estados Americanos (s.f.)

16 Véase a González Pereira (2000, p. 1252) y a Arrarte Arisnabarreta (2018).
} 
Según el artículo 2 de la CIDIP II, solo las medidas cautelares adoptadas por un órgano jurisdiccional competente sobre el fondo del asunto pueden ser reconocidas y ejecutadas en otro Estado parte. En otras palabras, el tribunal estatal requirente tiene una competencia implícita para adoptar medidas cautelares relativas al litigio, siendo que su condición para conocer sobre el fondo -según sus normas nacionales- es condición suficiente para adoptar las medidas cautelares ${ }^{17}$.

En cuanto al arbitraje comercial internacional, consideramos que la aplicación de este artículo es infructuosa e imposible, toda vez que está referido a jueces que tengan competencia sobre el fondo y, además, competencia especial para dictar medidas cautelares. En ese caso, no estaremos frente a un arbitraje comercial internacional, sino ante un proceso civil internacional.

Ahora bien, ¿un tribunal arbitral puede exigir a otro Estado miembro, en aplicación de este artículo, que se ejecuten las medidas cautelares dictadas por él mismo en forma de laudo? Consideramos que no. Según los términos de la CIDIP II, el tribunal que conocerá la materia será siempre un tribunal estatal. Por ello, un tribunal arbitral no puede invocar la aplicación de la CIDIP II para la ejecución automática (sin reconocimiento) de un laudo que contenga una medida cautelar internacional.

Por otro lado, el artículo 7 de la CIDIP II contempla la posibilidad de que el tribunal del Estado donde se tramitará el reconocimiento de una sentencia extranjera adopte una medida cautelar paralelamente al reconocimiento de la sentencia extranjera. Ello con la finalidad de garantizar la ejecución de la sentencia extranjera, evitando tener que esperar a que primero se nacionalice la sentencia extranjera. Consideramos que esta posibilidad ha sido contemplada exclusivamente para las sentencias extranjeras emitidas por tribunales nacionales, excluyéndose así a los laudos arbitrales emitidos en el extranjero.

El artículo 10 de la CIDIP II es una norma que se limita a consentir una disociación entre el proceso principal y el proceso cautelar, en tanto el concepto de tutela cautelar es autónomo por la naturaleza de los derechos que garantiza. Coincidimos con la doctrina en señalar que este artículo otorga a los tribunales estatales la capacidad de adoptar medidas cautelares de carácter urgente, las cuales recaerán exclusivamente sobre los bienes y personas que se encuentran en territorio peruano, en auxilio de un arbitraje comercial internacional con sede en el extranjero. La necesidad de tutela cautelar urgente se efectiviza no solo gracias a la cercanía del tribunal con los bienes o personas, sino -en gran parte- porque el tribunal estatal posee de ius imperium dentro de su territorio.

Otra norma de rango internacional que, en el Perú, coadyuva a la adopción de medidas cautelares en apoyo de un arbitraje comercial internacional con sede en el extranjero es la Ley Modelo de la CNUDMI. Específicamente, el artículo $17 \mathrm{~J}$ de la norma:

Artículo 17 J.- Medidas cautelares dictadas por el tribunal

El tribunal gozará de la misma competencia para dictar medidas cautelares al servicio de actuaciones arbitrales, con independencia de que éstas se sustancien o no en el país de su jurisdicción, que la que disfruta al servicio de actuaciones judiciales. El tribunal ejercerá dicha competencia de conformidad con sus propios procedimientos y teniendo en cuenta los rasgos distintivos de un arbitraje comercial internacional (1985).

Este artículo reconoce el esquema que hemos venido estudiando: existe una competencia sobre el fondo y una competencia especial para la adopción de medidas cautelares internacionales. Conforme a este artículo, concluimos que la potestad del tribunal arbitral para dictar medidas cautelares está implícita en el convenio arbitral, salvo pacto en contrario. En otras palabras, al existir una manifestación expresa de las partes para que los árbitros dicten medidas cautelares, se estará a lo que dispongan (Garcimartín Alférez, 1996, p. 189).

De esta manera, se desprende claramente que los tribunales (entiéndase, estatales) tienen competencia judicial internacional para dictar medidas cautelares, aun cuando carecen de competencia para conocer sobre el fondo del asunto. Esta última competencia se encuentra reservada, lógicamente, al tribunal arbitral, cuyo lugar de la sede puede ser dentro o fuera del territorio nacional.

\section{Normas de fuente nacional}

Delimitado el ámbito de aplicación de la CIDIP II, queda todavía un aspecto por determinar. Esto es,

17 En el Perú no existe jurisprudencia acerca de la cooperación judicial internacional en materia cautelar. Sin embargo, el caso más emblemático es el caso Aguinda Salazar, María c. Chevron Corporation (2013), que involucra una medida cautelar solicitada en Ecuador cuya ejecución se solicitó en los tribunales estatales de Argentina. Para más información, consúltese Requejo Isidro (2013, pp. 581-585). 
cuáles son las normas de competencia judicial internacional contempladas en la legislación peruana para adoptar medidas cautelares en apoyo de un arbitraje comercial internacional.

Debemos preguntarnos si la disposición del artículo $17 \mathrm{~J}$ de la Ley Modelo de la CNUDMI fue adoptada por la Ley de Arbitraje peruana. Conforme indica un sector de la doctrina nacional, no existe norma peruana expresa que habilite a los jueces a dictar medidas cautelares en apoyo de un arbitraje comercial internacional, lo cual, a nuestro criterio, resulta impreciso ${ }^{18}$.

El artículo 1 numeral 2 de la Ley de Arbitraje peruana señala que las normas contenidas en los incisos 1, 2, 3, 5 y 6 del artículo 8 se aplicarán "aun cuando el lugar del arbitraje se halle fuera del Perú" (Decreto Legislativo 1071, 2008). Esto significa que el legislador ha decidido que las normas que menciona el artículo 1 numeral 2 son normas imperativas de aplicación inmediata, independientemente del lugar de la sede del arbitraje, el cual puede ser fuera del Perú.

Entre estas normas aplicables a los arbitrajes internacionales con sede en el extranjero, ¿existe una disposición referida a la adopción de medidas cautelares? Por supuesto. En ese sentido, el artículo 8 numeral 2 señala lo siguiente:

Artículo 8.- Competencia en la colaboración y control judicial

\begin{abstract}
2. Para la adopción judicial de medidas cautelares será competente el juez subespecializado en lo comercial o, en su defecto, el juez especializado en lo civil del lugar en que la medida deba ser ejecutada o el del lugar donde las medidas deban producir su eficacia. Cuando la medida cautelar deba adoptarse o ejecutarse en el extranjero se estará a los tratados sobre ejecución de medidas cautelares en el extranjero o a la legislación nacional aplicable (Decreto Legislativo 1071,2008 ).
\end{abstract}

Este artículo recoge el mismo criterio para la adopción de las medidas cautelares, recogido en los artículos 10 de la CIDIP II y el $17 \mathrm{~J}$ de la Ley Modelo de la CNUDMI. Es aquel que establece que el juez del lugar donde la medida cautelar deba ser ejecutada o deba producir certeza, es competente para adoptar las medidas cautelares.

Interpretando el principio de la tutela jurisdiccional internacional efectiva conjuntamente al artícu- lo 1 numeral 2 de la Ley de Arbitraje peruana, concluimos que sí se reconoce expresamente que los tribunales estatales peruanos tienen competencia especial para dictar medidas cautelares en auxilio de un arbitraje con sede en el extranjero. Este último es el competente para conocer el fondo de la controversia. Coincidimos con la doctrina nacional en afirmar que la tutela cautelar es un derecho fundamental y, como tal, permite la adopción de medidas cautelares en el extranjero. Sin embargo, este argumento es el fundamento de la tutela cautelar internacional, recogido expresamente en la Ley de Arbitraje peruana.

Habiendo respondido afirmativamente una de las incógnitas del presente artículo, es necesario ahondar en los límites de esta potestad cautelar. En cuanto a la ley para la adopción de la medida cautelar, conforme a la lex loci arbitri, será aplicable la legislación peruana.

El artículo 47 de la Ley de Arbitraje peruana contempla las reglas de la tutela cautelar en el arbitraje. Cabe resaltar que este artículo no está contemplado en el artículo 1 numeral 2 de la Ley de Arbitraje peruana. Esto, creemos, tiene su razón de ser en tanto este artículo se refiere a la adopción de medidas cautelares adoptadas por un tribunal estatal peruano o un tribunal arbitral con sede en Perú.

¿La no inclusión de este artículo menoscaba la posibilidad de adoptar medidas cautelares a favor de un arbitraje en el extranjero? Consideramos que no. Como hemos desarrollado en el presente artículo, en tanto la tutela cautelar internacional es un derecho que forma parte de la tutela jurisdiccional internacional efectiva y la Ley de Arbitraje peruana es monista, las disposiciones del artículo 47 sobre las reglas de la tutela cautelar en el arbitraje comercial internacional se aplicarán a aquellas medidas cautelares dictadas en auxilio de un arbitraje con sede en el extranjero.

Sin embargo, este criterio no ha sido adoptado por los tribunales estatales peruanos. A modo de ejemplo, el juez del Segundo Juzgado Civil Subespecialidad Comercial de Lima -mediante la Resolución 1-, desestimó una medida cautelar fuera del proceso, solicitada por Acer Comercial S.R.L. contra Sun Drilling S.R.L. En este caso, Acer Comercial S.R.L. solicitó al juzgado que ordene a Sun Drilling S.R.L. abstenerse de iniciar acciones legales y/o judiciales dirigidas a reclamar el pago de una deuda derivada de un contrato comercial celebrado por

18 Véase a Pezo Arévalo (2014, pp. 79-83) y Arrarte Arisnabarreta (2018). 
ambas partes. El juez advirtió que existía una cláusula de sometimiento a un tribunal arbitral con sede en Houston, Texas; al momento de solicitar la medida cautelar no había comenzado arbitraje alguno. El juez concluyó que no era competente para adoptar una medida cautelar dado que existía una cláusula arbitral con sede en el extranjero (Expediente 3347-2010, 2010).

En nuestra opinión acerca de este caso, el juez peruano ignora que la Ley de Arbitraje peruana -al ser monista- contempla la posibilidad de adoptar medidas cautelares fuera y dentro del proceso, incluso cuando la sede del arbitraje sea en el extranjero, sin que ello implique una renuncia al arbitraje. Claramente, una solicitud cautelar dirigida hacia un tribunal peruano, el cual no es competente sobre el fondo, no afecta la competencia del tribunal arbitral con sede en Houston, Texas. Será este tribunal el único competente para conocer sobre el fondo del asunto de la controversia y decidir sobre su propia competencia, conforme al principio Kompetenz-Kompetenz. No contemplar esta posibilidad sería afectar gravosamente la tutela cautelar internacional de las partes.

En la jurisprudencia comparada, es conocida la sentencia del Tribunal Superior de Justicia de Inglaterra y Gales, en el asunto Mobil Cerro Negro Limited c. Petróleos de Venezuela S.A. En aplicación de la Arbitration Act de 1996, el juez de primera instancia concedió una Mareva injunction fuera del proceso, la cual ordenó el embargo de bienes por una significativa suma de dinero, aun cuando el arbitraje se daría con sede en Nueva York. Sin embargo, en segunda instancia, la medida cautelar fue levantada al entenderse que no existía vínculo ni bienes embargables el Reino Unido.

De similar manera, en España, mediante las resoluciones de 12 de marzo de 2004 y 21 de junio de 2006, el Juzgado de Primera Instancia número 42 de Madrid resolvió conceder una medida cautelar a favor de una constructora española que ordenaba a una entidad pakistaní no ejecutar unos avales en España por un supuesto incumplimiento de contrato de construcción de subestaciones eléctricas (citado en López de Argumedo Piñeiro \& Menéndez de la Cuesta Lamas, s.f.). A criterio del juzgado, no se podían ejecutar los avales hasta que la controversia sea resuelta por medio de un arbitraje administrado por la Cámara de Comercio Internacional (en adelante, $\mathrm{CCl}$ ). En el mismo sentido, el Juzgado de Santa María de La Real Nieva, mediante resolución del 10 de agosto de 2007, estimó una medida cautelar a favor de un productor local de vino, ordenando que este debía continuar proporcionando sus productos al distribuidor, el cual se negaba a recibirlos alegando incumplimientos contractuales (citado en López de Argumedo Piñeiro \& Menéndez de la Cuesta Lamas, s.f.). En ambos casos, los tribunales españoles estimaron las medidas cautelares porque sus efectos debían producirse en España.

Hasta este punto, podemos concluir que

a) De conformidad con el artículo 47 numeral 4 de la Ley de Arbitraje peruana, puede solicitarse medidas cautelares a un tribunal estatal peruano antes de la constitución del arbitraje con sede en el extranjero. Ahora bien, enmarcados en un arbitraje comercial internacional, es obligación del juez peruano que, ejecutada la medida cautelar, se contemple un plazo mayor al previsto por la ley (actualmente: diez días para iniciar el arbitraje y noventa para que la constitución del tribunal arbitral) tomando en cuenta que estamos frente a un arbitraje comercial internacional el cual requerirá de mayor tiempo para su constitución.

b) Si la medida cautelar se adopta antes de la constitución del tribunal arbitral, esta puede ser, de manera muy excepcional, inaudita altera partes. En cambio, si es solicitada después de la constitución del tribunal arbitral, deberá correrse traslado de la demanda a la parte afectada.

c) Conforme al artículo 47 numeral 8, previa autorización del tribunal arbitral, se puede solicitar ante un tribunal estatal la adopción y ejecución de una medida cautelar sobre bienes situados en Perú. Esto aplica incluso para los casos en que el arbitraje tiene sede en el extranjero.

d) Finalmente, el tribunal peruano deberá adecuar las medidas cautelares a fin de salvaguardar los intereses del arbitraje comercial internacional. Por ello, sugerimos que se puedan adoptar las siguientes medidas cautelares reconocidas por la doctrina internacional (Gómez Jene, 2018, pp. 328-329) ${ }^{19}$, siempre y cuando los bienes o las personas objeto de las medidas cautelares se encuentren en territorio peruano:

19 A mayor entendimiento, véase a Born (2014, pp. 2484-2502). 
- Orders Preserving Status Quo: aquellas destinadas a preservar un status quo entre las partes. A modo de ejemplo: no ejecutar una carta fianza o aval, aunque se den las circunstancias para ello.

- Orders Prohibiting Aggravation of Parties' Disputes: destinadas a no agravar la disputa entre las partes. Un caso muy conocido es la exigencia de la confidencialidad en la relación comercial.

- Orders Requiring Specific Performance of Contractual Obligations: aquellas cuyo objetivo es que se cumpla parcialmente con ciertas obligaciones de un contrato. En el caso de un contrato de obra, es para impedir que una de las partes incurra en mayores gastos.

- Orders Requiring Security for Underlying Claims: destinadas a evitar una desinversión del demandado sobre los bienes que tenga en el territorio nacional.

- Orders Requiring Security for Costs: aquellas que buscan asegurar los costos del arbitaje.

- Orders for Inspection of Property: destinadas a inspeccionar un lugar en concreto dentro del territorio peruano.

- Antisuit Orders: destinadas a evitar que alguna de las partes plantee la disputa ante un tribunal estatal, evitando su obligación de ir a arbitraje comercial internacional.

\section{RECONOCIMIENTO DE MEDIDAS CAUTE- LARES DICTADAS EN EL EXTRANJERO DEN- TRO DEL ARBITRAJE COMERCIAL INTER- NACIONAL}

Luego de estudiar la competencia y ley aplicable para la adopción y ejecución por parte de los tribunales estatales de medidas cautelares en apoyo de un arbitraje con sede en el extranjero, debemos dar respuesta a la segunda interrogante acerca de si un laudo dictado en el extranjero puede ser reconocido en el Perú.

Siempre que los presupuestos que dieron lugar a su adopción no se alteren, es posible que la decisión cautelar tenga calidad de cosa juzgada. Así,

debe atenderse a la naturaleza de la tutela cautelar, que no es otra que la que pretende garantizar la eficacia de los resultados que pue- dan llegar a alcanzarse en el proceso principal, de manera que lo razonable es entender que la cosa juzgada debe predicarse de las resoluciones cautelares cuando se mantienen los presupuestos para la adopción de la medida (Barona Vilar, 2018, pp. 732-733).

Para determinar si es posible ejecutar una resolución cautelar emitida fuera del Perú será necesario acudir a las fuentes internacionales y nacionales.

\section{A. Normas de fuente internacional}

Con respecto al arbitraje comercial internacional, uno de los convenios internacionales relevantes de codificación y/o armonización en Latinoamérica es la Convención Interamericana sobre Arbitraje Comercial Internacional de 1975. Sin embargo, la aplicación de esta quedó en segundo plano dado el alto número de ratificaciones de la Convención de las Naciones Unidas sobre el Reconocimiento y la Ejecución de las Sentencias Arbitrales Extranjeras, aprobado por la CNUDMI (1958), de aplicación casi universal y ratificada por el Perú.

Sin embargo, la posibilidad de reconocer un laudo que contenga una medida cautelar a través de la referida convención no es unánimemente reconocida en la doctrina internacional (Mallandrich Miret, 2010, pp. 293-294). Veamos las posturas actuales:

- En contra: para un sector de la doctrina, las actuaciones arbitrales que contengan una medida cautelar no pueden ser reconocidas en amparo de la Convención, sobre todo en los casos en que la medida cautelar no adopta la forma de laudo. En segundo lugar, en caso fuera un laudo, esta disposición cautelar carece de carácter definitivo.

- A favor: otro sector de la doctrina considera que la negación de reconocimiento se debe a una lectura formalista y literal de la Convención. Sostienen que más bien esta interpretación debe ser finalista, a partir de que la Convención persigue facilitar el reconocimiento de laudos extranjeros.

\section{B. Normas de fuente nacional}

De manera general, la normativa de fuente interna peruana sobre arbitraje sí contempla el exequátur de medidas cautelares adoptadas por tribunales arbitrales con sede en el extranjero. Así, conforme al artículo 8 numeral 2 y el artículo 48 numeral 4 de la Ley de Arbitraje peruana (artículo incluido para arbitrajes con sede 
en el extranjero, es decir, los que emitieron estos laudos) ${ }^{20}$, las medidas cautelares internacionales revestidas de forma de laudo podrán ser reconocidas y ejecutadas dentro del Perú conforme a lo dispuesto por los tratados suscritos por el Perú o, en defecto de los mismos, conforme la ley nacional, siempre que la parte interesada presente el original o una copia del laudo. Una vez la solicitud haya sido admitida por el tribunal, se otorga un plazo de diez días a la parte afectada para que se pronuncie. Posteriormente, se decide sobre la ejecución de aquella.

La jurisprudencia sobre reconocimiento de laudos extranjeros en Perú es escasa. No obstante, una muestra de ella es la decisión adoptada por la Segunda Sala Civil Subespecializada en Materia Comercial de la Corte Superior de Justicia de Lima, en la Resolución 5 del Expediente 199-2018. En esta, la Sala declara fundada la solicitud de Aguaytía Energy del Perú S.R.L. y reconoce en su totalidad la Decisión Cautelar del 6 de marzo de 2018, emitida en el marco del arbitraje internacional administrado por la Corte Internacional de Arbitraje de la Cámara de Comercio Internacional (CCI) que impuso determinadas conductas a la empresa Maple Gas Corporation del Perú S.R.L.

Resultan positivos los fundamentos segundo y décimo cuarto de la mencionada resolución. En esta se considera que, al no ser aplicable la Convención de Nueva York de 1958 para el reconocimiento de laudos extranjeros que contengan una medida cautelar dictada por un tribunal arbitral, se deben utilizar las reglas de la Ley de Arbitraje peruana; así como que la decisión cautelar no vulnera el orden público internacional peruano. Consideramos correcto este fallo al reconocer a las partes su derecho a la tutela cautelar internacional.
Finalmente, el cumplimiento de una medida cautelar adoptada por un tribunal arbitral extranjero supone para el Perú un altísimo grado de compromiso. Debemos mencionar que el exequátur de medidas cautelares (judiciales o arbitrales) es una medida que podría conllevar a una frustración de la medida. Sin embargo, consideramos que esto no afecta la tutela cautelar internacional en Perú, en tanto que las partes pueden solicitar la adopción de una medida cautelar en este Estado, aun cuando el arbitraje está situado en el extranjero. A nuestro entender, tiene más sentido que un tribunal peruano, con ius imperium sobre su territorio, ordene directamente la medida cautelar, antes que si la dictara un tribunal arbitral.

Muy aparte de este reconocimiento forzoso, las partes buscan el cumplimiento espontáneo de los laudos, evitando así el engorroso y largo procedimiento del exequátur. A esto le llamamos cumplimiento espontáneo.

\section{CONCLUSIONES}

\section{- $\quad$ El arbitraje como jurisdicción}

El arbitraje en el Perú es jurisdicción. Así ha sido reconocido por el Tribunal Constitucional y el artículo 139 de la Constitución Política del Perú. Este reconocimiento no debe generar una desconfianza en el arbitraje sino todo lo contrario. Este revestimiento constitucional coadyuva a la finalidad del arbitraje: la justa resolución de controversias entre privados. No cabe duda de que el arbitraje es una justicia privada, que nace del convenio arbitral, el cual responde a la autonomía de la voluntad de las partes.

e. La autoridad judicial que conoce de la ejecución de la medida cautelar podrá rechazar la solicitud, cuando la medida cautelar sea incompatible con sus facultades, a menos que decida reformular la medida para ajustarla a sus propias facultades y procedimientos a efectos de poderla ejecutar, sin modificar su contenido ni desnaturalizarla (Decreto Legislativo 1071, 2008). 
Aun así, sigue siendo un método para alcanzar justicia; en ese sentido, los árbitros están investidos de jurisdicción.

- La tutela cautelar internacional en el arbitraje comercial internacional

La tutela cautelar internacional es imperativa aun en el arbitraje. Una de las normas de carácter imperativo que contempla la Ley de Arbitraje peruana es la adopción, ejecución y reconocimiento de medidas cautelares. En ese sentido, esta relación entre judicatura y arbitraje se enmarca en el campo de la complementariedad y la cooperación.

- $\quad$ El principio de cooperación entre los tribunales estatales e intervención mínima del arbitraje

La autonomía de la voluntad no es ilimitada ni ajena a las leyes nacionales. La ley nacional del lugar de la sede del arbitraje prescribe la autonomía de la voluntad de las partes, limita las facultades de los árbitros y establece su cooperación con los jueces. Además, al ser un mecanismo de resolución de conflictos, el arbitraje se debe desarrollar en el marco de un Estado Constitucional de Derecho, que exige ciertas garantías para su correcto desenvolvimiento.

- Es posible adoptar medidas cautelares en apoyo de un arbitraje extranjero

En concordancia con la CIDIP II y la Ley de Arbitraje peruana, consideramos que sí es posible la adopción de una medida cautelar en auxilio de un arbitraje con sede en el extranjero. Si bien la CIDIP II es un instrumento importante en materia de tutela cautelar internacional, consideramos que su efectividad se ve reducida por el reducido número de los Estados miembros que la han suscrito: apenas siete de los treinta y cinco Estados que forman parte de la Organización de los Estados Americanos y ninguna adhesión de un Estado fuera de esta.

Asimismo, sobre la legislación nacional, creemos que la razón por la que el artículo 47 no está contemplado en el artículo 1 numeral 2 es porque el primero se refiere a la potestad de los árbitros de dictar medidas cautelares siempre que la sede sea Perú.

\section{REFERENCIAS}

All, P. M., \& Pallarés, B. (2019). La regulación del arbitraje comercial internacional en los tratados internacionales. En Esplugues Mota, C. (Ed.), Tratado de Arbitraje Comercial interno e internacional en Iberoamérica (pp. 99-122). Tirant lo Blanch.

Arrarte Arisnabarreta, A. M. (27 de abril de 2018). Los jueces peruanos sí pueden conceder cautelares para ejecutar un laudo dictado en el extranjero. Diario Gestión. https://gestion.pe/ blog/agenda-legal/2018/04/los-jueces-peruanos-si-pueden-conceder-cautelares-para-ejecutar-un-laudo-dictado-en-el-extranjero.html/

Barona Vilar, S. (2007). Arbitraje en España: a la búsqueda de un lugar adecuado en el marco de la justicia. En Barona Vilar, S. (dir.) Arbitraje y Justicia en el Siglo XXI (pp. 25-58). Thomson Reuters Civitas.

(2016). 'Justicia integral' y 'access to justice': Crisis y evolución del paradigma. En Barona Vilar, S. (Ed.), Mediación, Arbitraje y Jurisdicción en el actual paradigma de justicia (pp. 31-55). Thomson Reuters Civitas.

(2018). Proceso y procedimiento cautelar. En Montero Aroca, J., Gómez Colomer, J. L., Barona Vilar, S., \& Calderón Cuadrado, M. P. (Eds.) Derecho Jurisdiccional II. Proceso Civil (26ta ed., pp. 727-744). Tirant lo Blanch.

Born, G. (2009). The principle of judicial noninterference in international arbitral proceedings. University of Pennsylvania Journal of International Law, 30(4), 999-1033. https:// scholarship.law.upenn.edu/cgi/viewcontent. cgi ?article $=1859 \&$ context $=$ jil

(2014). International Commercial Arbitration. Kluwer Law International.

Calamandrei, P. (1945). Introducción al estudio sistemático de las providencias cautelares. Bibliografía Argentina.

Caivano, R. J. (2015). El Rol del Poder Judicial en el Arbitraje Comercial Internacional. En Organización de los Estados Americanos (OEA), Arbitraje Comercial Internacional, reconocimiento y ejecución de sentencias y laudos arbitrales extranjeros (pp. 97-120). Secretaría General de la OEA. http://www.oas.org/es/ sla/ddi/docs/arbitraje_comercial_publicaciones_Reconocimiento_y_Ejecucion_de_ Sentencias_y_Laudos_Arbitrales_Extranjeros_2015.pdf

Delgado Barreto, C., Delgado Menéndez, M. A., \& Candela Sánchez, C. L. (2010). Introducción al 
derecho internacional privado (3era. ed., tomo I). Fondo Editorial de la Pontificia Universidad Católica del Perú.

Esis Villarroel, I. (2019). El rol de las instituciones arbitrales en el desarrollo del arbitraje internacional. Revista de Direito Internacional, 16(1), 36-52. https://doi.org/10.5102/rdi.v16i1.5931

Esplugues Mota, C. (2014) El derecho internacional privado: características generales. En C. Esplugues Mota, J.L. Iglesias Buhigues, G. Palao Moreno (eds.), Derecho internacional privado (8va ed., pp. 75-96). Tirant lo Blanch.

(2019). El arbitraje comercial en Iberoamérica: una realidad consolidada no exenta de tensiones. En C. Esplugues Mota (Ed.), Tratado de Arbitraje Comercial interno e internacional en Iberoamérica (pp. 49-98). Tirant lo Blanch.

(2020). La Convención de Singapur de 2018 sobre Mediación y la creación de un título deslocalizado dotado de fuerza ejecutiva: una apuesta novedosa, y un mal relato. Revista Española de Derecho Internacional, 72(1), 53-80. https://doi.org/10.17103/redi.72.1.2020.1.02

Fernández Rozas, J. C., Arenas García, R., \& de Miguel Asensio, P. A. (2011). Derecho de los negocios internacional (3ra ed.). lustel.

Fernández Rozas, J. C., Sánchez Lorenzo, S. A., \& Stampa, G. (2018). Principios Generales del Arbitraje. Tirant lo Blanch.

Garcimartín Alferez, F. (1996). Régimen de las medidas cautelares en el comercio internacional. McGraw-Hill; Interamericana De España.

Gómez Jene, M. (2018). Arbitraje comercial internacional. Thomson Reuters Civitas.

González Pereira, O. (2000). Cooperación Cautelar en el derecho internacional privado. Revista Jurisprudencia Argentina, (3), 1242-1262.

Lapiedra Alcamí, R. (2008). Medidas cautelares en el arbitraje comercial internacional. Tirant lo Blanch.

Lew, J. D. M. (2006). Achieving a Dream: Autonomous Arbitration. Arbitration International, 22(2), 179-204. https://doi.org/10.1093/arbitration/22.2.179

López de Argumedo Piñeiro, A., \& Menéndez de la Cuesta Lamas, K. (s.f.). La intervención judicial en el arbitraje: análisis de juris- prudencia española reciente. https://www. uria.com/documentos/publicaciones/2568/ documento/103ala.pdf?id=2598

Lorca Navarrete, A. M. (1997). Manual de derecho de arbitraje interno e internacional. Civitas.

Mallandrich Miret, N. (2010). Medidas cautelares y arbitraje. Atelier.

Monroy Cabra, M. G. (2012). Tratado de Derecho Internacional Privado (7ma ed.). Editorial Temis S.A.

Organización de los Estados Americanos. (s.f.). Información general del tratado B-42: Convención Interamericana sobre cumplimiento de medidas cautelares. http://www.oas.org/juridico/spanish/firmas/b-42.html

Palao Moreno, G. (2007). Nuevas tendencias en materia de arbitraje comercial internacional en América Latina. En S. Barona Vilar (Dir.), Arbitraje y Justicia en el Siglo XXI. Civitas.

Pezo Arévalo, E. E. (2014). ¿Puede un juez peruano dictar una medida cautelar en apoyo de un arbitraje con sede en el extranjero?. Revista de Economía y Derecho de la UPC, 11(41), 61-88.

Pinto Rocha, J. L. (2019). El arbitraje en el Perú. En C. Esplugues Mota (Ed.), Tratado de Arbitraje Comercial interno e internacional en Iberoamérica. Tirant lo Blanch.

Queen Mary University of London \& White \& Case (2018). International arbitration survey: the evolution of international arbitration. School of International Arbitration Centre for Commercial Studies. http://www.arbitration.qmul. ac.uk/research/2018/

Quiroga León, A. (2017). La naturaleza procesal del arbitraje. Biblioteca de Arbitraje del Estudio Mario Castillo Freyre.

Radicati di Brozolo, L. G. (2013). Las normas imperativas y el arbitraje internacional. En Gaillard, E., \& Fernández Arroyo, D. (Eds.), Cuestiones claves del arbitraje internacional. Editorial Universidad del Rosario. https://doi. org/10.2307/j.ctvm2044x.11

Requejo Isidro, M. (2013). Aguinda v. Texaco en la fase de Exequátur: análisis del primer tropiezo. Dereito: Revista xurídica da Universidade de Santiago de Compostela, 22(Ext), 581-585. http://www.usc.es/revistas/index.php/dereito/article/view/1239/1567 
Rodríguez Mejía, M. (2013). Medidas cautelares en el proceso arbitral. Editorial Universidad Externado de Colombia.

Sandler Obregón, V. (2016). Nociones generales de Arbitraje Internacional. En Comité Jurídico Interamericano de la Organización de los Estados Americanos (OEA), XLIII Curso de Derecho Internacional. Secretaría General de la OEA, 431462. http://www.oas.org/es/sla/ddi/docs/ publicaciones_digital_XLIII_curso_derecho_internacional_2016_Publicacion_Completa.pdf

Tellechea Bergman, E. (2017). Hacia una necesaria profundización de la cooperación jurisdiccional internacional y el reconocimiento de los fallos extranjeros en el ámbito interamericano. Revista de Derecho de la Universidad de Montevideo, (32), 103-124. http://revistaderecho. um.edu.uy/wp-content/uploads/2018/04/Revista-32.pdf

Virgós Soriano, M., \& Garcimartín Alférez, F. (2007). Derecho Procesal Civil Internacional Litigación Internacional (2da ed.). Thomson Reuters Civitas.

Yesilirmak, A. (2005). Provisional measures in international commercial arbitration. Kluwer Law International.

\section{LEGISLACIÓN, JURISPRUDENCIA Y OTROS DOCU- MENTOS LEGALES}

Comisión de las Naciones Unidas para el Derecho Mercantil Internacional, Ley Modelo de la CNUDMI sobre Arbitraje Comercial Internacional 1985 con las enmiendas aprobadas en 2006, Publicación de las Naciones Unidas, número de venta S.08.V.4 (2008).

Constitución Política del Perú de 1993 [Const.].

Convención de las Naciones Unidas sobre el Reconocimiento y Ejecución de Sentencias Arbitrales Extranjeras (Convención de Nueva York), 10 de junio de 1958, 330 U.N.T.S. 3.

Convención Interamericana sobre arbitraje comercial internacional (Convención de Panamá), 30 de enero de 1975, O.A.S.T.S. No. 42., 1438 U.N.T.S. 245

Convención Interamericana sobre cumplimiento de medidas cautelares. 8 de mayo de 1979, O.A.S.T.S. No. 52.
Corte Suprema de Justicia de la Nación Argentina (CSJN), 22/5/2013, Aguinda Salazar, María c. Chevron Corporation, Fallos (2013-336-I-503) (Arg.).

Decreto Legislativo 1071, Decreto Legislativo que norma el arbitraje, Diario Oficial El Peruano, 28 de junio de 2008 (Perú).

Decreto Supremo 014-2008-JUS, Reglamento de la Ley 26872 Ley de Conciliación, Diario Oficial EI Peruano, 29 de agosto de 2008 (Perú).

Directiva 2008/52/CE, del Parlamento Europeo y del Consejo de 21 de mayo de 2008 sobre ciertos aspectos de la mediación en asuntos civiles y mercantiles, 2008 O.J. (L 136) 3.

Juzgado de Santa María de La Real Nieva, Castilla y León. Resolución del 10 de agosto de 2007 (Esp.).

Ley 26872, Ley de Conciliación, Diario Oficial El Peruano, 31 de noviembre de 1997 (Perú).

Mobil Cerro Negro Ltd c. Petroleos de Venezuela SA [2008] EWHC (Comm) 532, [2008] 2 All ER (Comm.) 1034 (Inglaterra)

Res. 73/198, Convención de las Naciones Unidas sobre los acuerdos de transacción internacionales resultantes de la mediación (Convención de Singapur sobre la Mediación) (20 de diciembre de 2018).

S. Juz. Prim. 42 de Madrid, 12 de marzo de 2004 (Esp.).

S. Juz. Prim. 42 de Madrid, 21 de junio de 2006 (Esp.).

Segunda Sala Civil Subespecializada en Materia Comercial de la Corte Superior de Justicia de Lima, 22 de octubre de 2019, Resolución 5, Expediente 199-2018 (Perú).

Segundo Juzgado Civil Subespecialidad Comercial de Lima, 21 de mayo de 2010, Resolución 1, Expediente 3347-2010 (Perú).

Tratado de Derecho Procesal Internacional de Montevideo, 11 de enero de 1889.

Tratado de Derecho Procesal Internacional de Montevideo, 19 de marzo de 1940.

Tribunal Constitucional del Perú, 28 de enero de 2006, sentencia recaída en el Expediente 61672005-PHC/TC (Perú). 